\title{
Observation of Frost Heave of THF Clathrate Hydrate on Porous Glass Powder
}

\author{
Kunio Watanabe ${ }^{1}$, Kosuke Yokokawa ${ }^{2}$ and Yoshiko Muto Author ${ }^{3}$ \\ ${ }^{1}$ Department of Bioresources, Mie University, 1577 Kurima-machiya, Tsu 514-8507 \\ Japan; email kunio@bio.mie-u.ac.jp \\ ${ }^{2}$ Nippon Tansan Co. Ltd, 1-10-15, Hkataeki-minami, Hakataku, Fukuoka 812-0016 \\ Japan; email: k-y@mub.biglobe.ne.jp \\ ${ }^{3}$ Ddepartment of International Environmental \& Agricultural Sciences, Tokyo \\ University of Agriculture \& Technology, 3-5-8 Saiwaicho, Fuchu, Tokyo 183-8509 \\ Japan; email: mutoy@cc.tuat.ac.jp
}

\begin{abstract}
The formation processes of clathrate hydrate in porous glass powder saturated with a THF-water mixture were directly observed using directional cooling apparatus. As the cooling rate decreased, the THF hydrate grew while excluding glass particles and formed a lens like layer of hydrate in the same manner as in the phenomenon of ice lens formation in the freezing of soil. The growth rate of the hydrate lens was proportional to the degree of supercooling of the growth surface and was about $1 / 20$ th the growth rate of the hydrate layer in a THF-water mixture without glass particles. When sodium chloride was added to the system, the growth of the hydrate lens was inhibited depending on the salt concentration.
\end{abstract}

\section{Introduction}

When ground freezes, soil water forms ice in various shapes, including pore ice, granular ice, and layered ice from which all soil particles have been expelled. The ice layers, called ice lenses, sometimes cause severe frost heave. Although the conventional view treats frost heave and lens formation as unique attributes of water and soil, similar phenomena can occur in other substances (Hiroi et al. 1989; Mutou et al. 1998; Zhe et al. 2000). If soil is exposed to low temperatures or high pressure, not only ice but also gas hydrate can form within it. Gas hydrates formed in pores or into granular or lens-like shapes are sometimes observed in permafrost and undersea sediments (Dallimore and Collett 1997). The effects of soil particles on the thermal properties of tetrahydrofuran (THF) hydrate (Rueff and Sloan 1985) and the static properties of methane hydrate in sand and clay (Chuvilin et al. 2000, 2002) 
have been investigated. However, there have been few direct observations of the formation of clathrate hydrates in freezing soils.

Clathrate hydrates are ice like solids in which water molecules form a crystalline lattice that is composed of many cavities occupied by guest molecules, such as certain gasses or volatile liquids. From the perspective of recent environmental and industrial concerns, the structures of various clathrate hydrates (Mak and McMullan 1965; Gough and Davidson 1971; Sloan 1990) and their thermal properties at equilibrium (Ross et al. 1981; Leaist et al. 1982; Handa et al. 1984) have been clarified. Since the formation and dissociation of clathrate hydrate are greatly affected by the solute, the dependence of the solute on the phase equilibrium conditions has been investigated (de Roo et al. 1983). However, the solute influences on the formation processes of clathrate hydrate have not been sufficiently elucidated.

Since gas hydrate forms under relatively high pressures and cold temperatures, the formation process has seldom been observed directly, except under special conditions (Uchida et al. 1999). In contrast, THF hydrate forms at atmospheric pressure at temperatures below $4.4{ }^{\circ} \mathrm{C}$. Therefore, THF can replace gas hydrate as a model crystal for observations (Nagashima et al. 2000; Iida et al. 2001). Here, we present the results of in situ observations of THF hydrate formation in a directionally freezing porous medium consisting of glass microparticles saturated with different concentrations of sodium chloride solution. The process of hydrate formation in a porous medium and the effect of solute concentration are discussed.

\section{Materials and Methods}

Sample. The porous powder used in the experiment consisted of uniform glass spheres $2.2 \mu \mathrm{m}$ in diameter. Table 1 lists the characteristics of the powder. The powder holds significant amounts of unfrozen water at subzero temperatures and has frost susceptibility (Watanabe et al. 2001). Distilled, deionized, and degassed water and tetrahydrofuran (THF) of $99.9 \%$ purity were used. THF is miscible in water and forms a structure II hydrate with water at a molar ratio of 1:17 (Gough and Davidson 1971). This hydrate melts at a temperature of $4.4{ }^{\circ} \mathrm{C}$ and $101.3 \mathrm{kPa}$, although the melting temperature varies between 0 and $4.4{ }^{\circ} \mathrm{C}$ depending on the $\mathrm{THF}$ concentration (Hanley et al. 1989). Although mass transfer at the liquid-gas interface controls the nucleation and crystal growth of gas hydrates, the mass transfer effects are eliminated for THF hydrate (Devarakonda et al. 1999). The physical properties of solutions and THF hydrate are listed in Table 2. Glass particles have no effect on the thermal properties of ice or THF hydrate (Rueff and Sloan 1985) and lower the phase equilibrium temperature of clathrate hydrate (Chuviline et al. 2000, 2002). 
Table 1 Physical properties of the glass powder.

\begin{tabular}{lll}
\hline Mean diameter & $\mu \mathrm{m}$ & 2.2 \\
Mean pore size & $\mathrm{nm}$ & 3.3 \\
Specific pore volume & $\mathrm{m}^{3} \mathrm{~kg}^{-1}$ & $0.3 \times 10^{-3}$ \\
Specific surface area & $\mathrm{m}^{2} \mathrm{~kg}^{-1}$ & $129 \times 10^{3}$ \\
Density & $\mathrm{kg} \mathrm{m}^{-3}$ & 2120 \\
Hydraulic cond. & $\mathrm{m} \mathrm{s}^{-1}$ & $1.9 \times 10^{-8}$ \\
\hline
\end{tabular}

Table 2 Physical properties of the solutions.

\begin{tabular}{|c|c|c|c|c|c|}
\hline & & 1:17 sol. & Hydrate & Water & Ice \\
\hline Thermal cond. & $\mathrm{Wm}^{-1} \mathrm{~K}^{-1}$ & $0.562^{\mathrm{a}}$ & $0.525^{\mathrm{a}}$ & 0.561 & 2.14 \\
\hline Specific heat & $\mathrm{kJ} \mathrm{kg}^{-1} \mathrm{~K}^{-1}$ & $4.21^{\mathrm{b}}$ & $2.123^{\mathrm{c}}$ & 4.217 & 2.11 \\
\hline Density & $\mathrm{kg} \mathrm{m}^{-3}$ & $997^{\mathrm{d}}$ & $997^{\mathrm{d}}$ & 1000 & 917 \\
\hline Melting point & ${ }^{\circ} \mathrm{C}$ & \multicolumn{2}{|l|}{$4.4^{\mathrm{e}}$} & \multicolumn{2}{|l|}{0} \\
\hline Latent heat & $\mathrm{kJ} \mathrm{kg}^{-1}$ & \multicolumn{2}{|l|}{$260^{c}$} & \multicolumn{2}{|c|}{333} \\
\hline Diffusion coef. & $m^{2} s^{-1}$ & - & - & $1.0 \times 10^{-9} \mathrm{f}$ & - \\
\hline
\end{tabular}

Values were obtained at $4.4{ }^{\circ} \mathrm{C}$ for THF-water solution at a molar ratio of 1:17 (1:17 sol.) and THF hydrate (Hydrate), and at $0{ }^{\circ} \mathrm{C}$ for water and ice. ${ }^{\mathrm{a}}$ Ross and Anderson (1982), ${ }^{\mathrm{b}}$ Iida et al. (2001), ${ }^{c}$ Leaist et al. (1982), ${ }^{\mathrm{d}}$ Gough and Davidson (1971). ${ }^{\mathrm{e}}$ Hanley et al. (1989), ${ }^{\mathrm{f}}$ Gillen et al. (1972).

Table $3 \mathrm{NaCl}$ concentration in solution and the ratio of solution to glass powder.

\begin{tabular}{lllll}
\hline Name & $C_{\text {int }}(\%)$ & $L L(\%)$ & $L L \times 1.1$ & $w(\%)$ \\
\hline S0 & 0 & 115 & 126.5 & 126.2 \\
S003 & 0.03 & 125 & 137.5 & 136.2 \\
S003w & 0.03 & 125 & 137.5 & 155.5 \\
S03 & 0.3 & 143 & 157.3 & 155.5 \\
S3 & 3 & 185 & 203.5 & 203.7 \\
\hline
\end{tabular}

Directional freezing experiment. A THF-water solution at a molar ratio of 1:17 was prepared with different sodium chloride concentrations. The solution was cooled to $10{ }^{\circ} \mathrm{C}$ in a sealed chamber and then mixed with the glass powder. The consistency of this sample changes markedly with the water content and solute concentration. Therefore, the initial water content was adjusted to be 1.1 times greater than the liquid limit (LL). Table 3 shows the initial sodium chloride concentration in the solution, the liquid limit, and the initial water content of the sample. Note that the water content used here was defined as the ratio of THF solution to the porous powder by mass. 
The sample was packed into a cylindrical glass cell with an internal diameter of 7.55 $\mathrm{mm}$ and a length of $150 \mathrm{~mm}$. To prevent evaporation, the cell was sealed with paraffin film. A temperature cell, which contained five copper-constantan thermocouples, accurate to $0.03{ }^{\circ} \mathrm{C}$, was also prepared using powder mixed with ethylene glycol instead of THF solution. The bottoms of the sample and temperature cells were soused in liquid nitrogen for a few seconds for seeding, and both cells were then cooled simultaneously using the directional cooling apparatus (Fig. 1). The temperatures of the top and bottom of the cell were held at different constant temperatures of $10{ }^{\circ} \mathrm{C}$ and $-4{ }^{\circ} \mathrm{C}$, respectively. An almost linear temperature gradient was established after $120 \mathrm{~min}$ had elapsed and the final temperature gradient was $0.14 \pm 0.15^{\circ} \mathrm{C} \mathrm{mm}^{-1}$. A digital video camera and recorder were placed by the cell and used to observe the formation of THF hydrate. The captured images were divided into a $0.04-\mathrm{mm}$ grid using a computer, and the location and temperature of the crystallization front were analyzed.

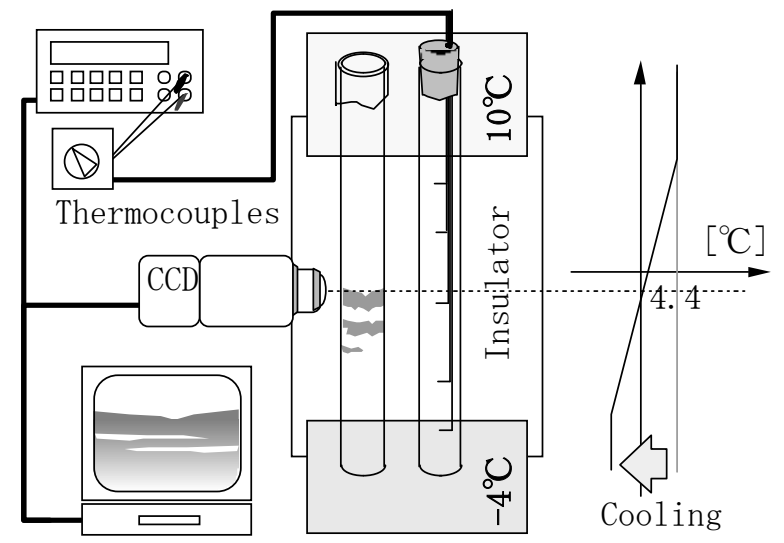

Fig. 1 Schematic illustration of the directional cooling experiment.

\section{Results}

Observation of THF hydrate formation in porous media. When different temperatures were applied to either end of a sample cell, the sample froze directionally beginning from the cold end. During sample cooling, intermittent layers of crystals that expelled glass particles were observed. Figure 2 shows the crystals observed in sample S0 $\left(C_{\text {init }}=0 \%\right)$, which was cooled for $24 \mathrm{~h}$. The scale bar indicates $1 \mathrm{~mm}$. In Fig. 2, the bottom is colder and the top is warmer; the porous medium appears white and the segregated crystals appear black or gray.

In the early stages of cooling, no crystal segregation was observed. When the rate of isotherm advance in the sample (the cooling rate) decreased below $1 \mu \mathrm{m} \mathrm{s}^{-1}$, the first crystal layer appeared and grew, while expelling glass powder. Once the crystal had grown a few $100 \mu \mathrm{m}$, it stopped growing, and new crystal layer then appeared in a warmer location than that where the previous layer had grown (Fig. 2, from bottom). 
Subsequently, a series of crystals formed intermittent layers in the direction perpendicular to the heat flow. The layers that formed later were thicker and clearer. After the cooling experiment, the warmest layer was taken from the cell and set on fire. It burned readily in air, demonstrating that the segregated crystal was THF hydrate. Here, we call such a layered crystal a hydrate lens due to its shape.

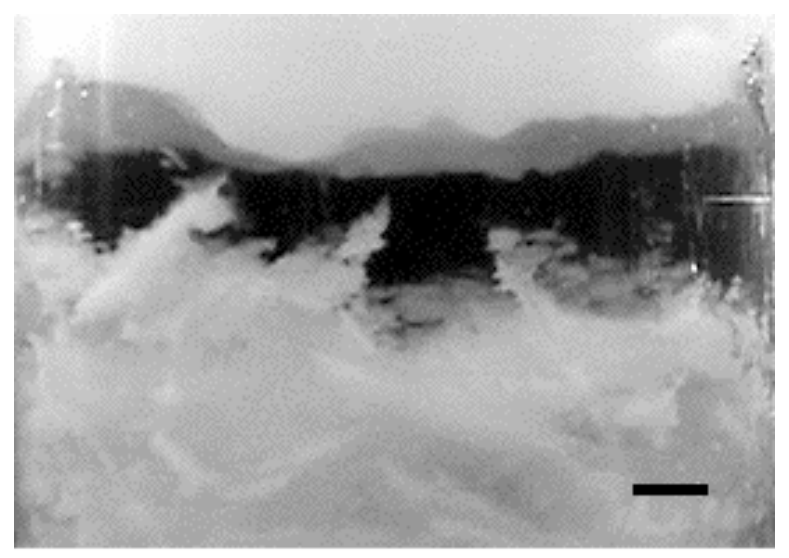

\section{Fig. 2 Crystallization in glass powder saturated with 1:17 THF solution.}

When sodium chloride was added to the system, the concentration and water content determined whether hydrate lenses formed in the sample (Fig. 3). The hydrate lenses formed readily when the salt concentration was low and the initial water content was high. As the salt concentration increased and the water content decreased, the shape of the hydrate lenses became unstable, and they no longer maintained a lenslike shape, but became dendrite-like. Little or no lens or dendrite formation occurred when the initial water content was lower than the liquid limit, especially with a high solute concentration.



Fig. 3 Diagram of the formation of a hydrate lens in glass powder. 
Hydrate lens growth. Figures 4 and 5 show the growth of the warmest hydrate lens and estimated temperature at the growth surface, respectively. The elapsed time was counted from the beginning of formation of the warmest hydrate lens. In each sample, the warmest hydrate lens grew rapidly initially, and then grew more slowly, and essentially stopped growing after $48 \mathrm{~h}$. The hydrate lens started to form at a temperature a few degrees lower than its melting temperature $\left(4.4{ }^{\circ} \mathrm{C}\right)$. The temperature at the growth surface increased with its growth. In the salt-free sample (S0), the final temperature at the growth surface of the warmest hydrate lens was 4.13 ${ }^{\circ} \mathrm{C}$, which was $0.27^{\circ} \mathrm{C}$ lower than the melting temperature. This may have resulted from lowering the phase equilibrium temperature of the THF hydrate due to the presence of glass particles.

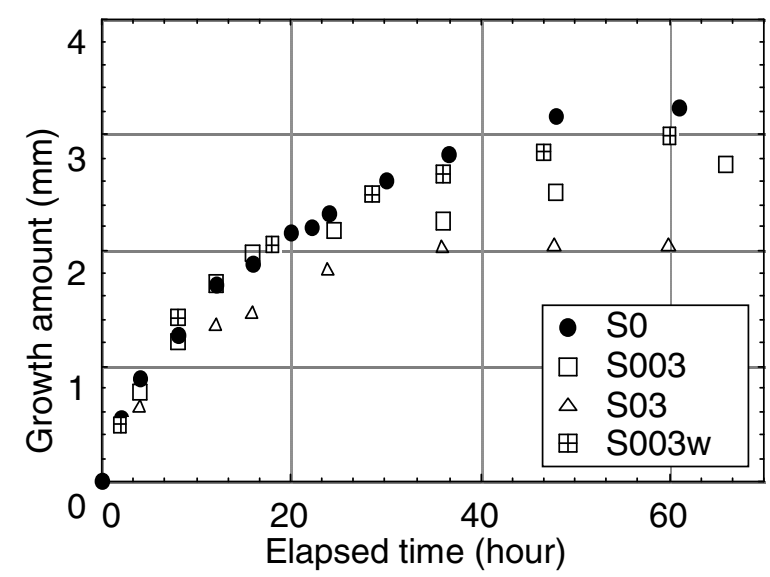

Fig. 4 Growth of the warmest hydrate lens.

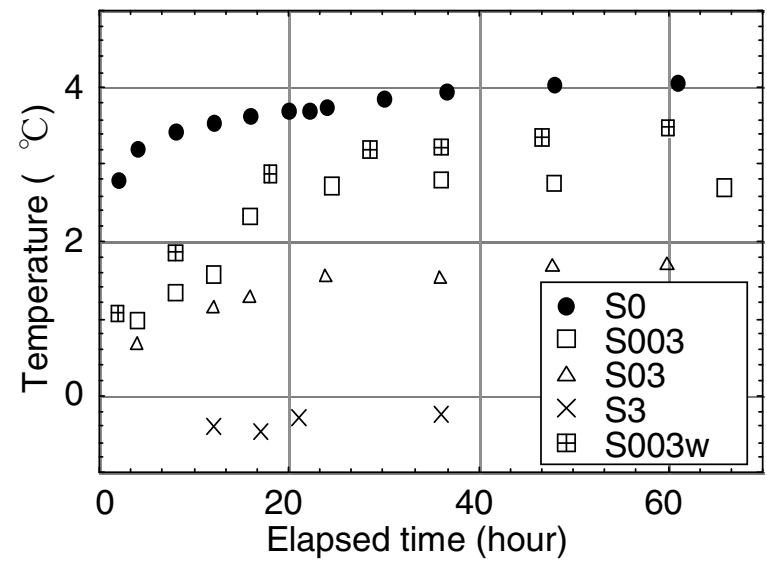

Fig. 5 Temperature at the growth surface of the warmest hydrate.

The hydrate lens became thinner with increasing initial sodium chloride concentration. For $48 \mathrm{~h}$, the warmest hydrate lens grew to $3.16,2.51$, and $2.03 \mathrm{~mm}$ thick in samples S0, S003, and S03, respectively (Fig. 4). For sample S3, dendrite-like formation 
was observed, not lenslike formation (Fig. 3). The temperature at the growth surface of the hydrate lens and dendrite at an elapsed time of $48 \mathrm{~h}$ were 4.04, 2.73, 1.68, and $-0.35{ }^{\circ} \mathrm{C}$ for samples S0, S003, S03, and S3, respectively. The temperature decreased with increasing initial salt concentration (Fig. 5).

Sample S003w is the one in which the initial salt concentration equaled that of S003 $(0.03 \%)$, but the initial water content was higher than in S003. Even if the sample had the same initial salt concentration, the hydrate lens grew thicker at a higher temperature in the water-rich environment (Figs. 4 and 5).

Growth rate and supercooling at the growth surface. Figure 6 shows the relationship between the growth rate and degree of supercooling, $T_{m}-T$, which was calculated from Figs. 4 and 5. Here, we used $T_{m}=4.4{ }^{\circ} \mathrm{C}$ for THF hydrate. Figure 6 also shows the growth rate of ice in water, with the formation of an ice lens in the same powder as used this experiment (Watanabe 2002), and THF hydrate in a 1:17 THF-water solution. The growth rate of the hydrate lens was linearly correlated with the degree of supercooling. Similar proportionality constants were observed in samples with different initial salt and water contents $(0.033,0.020,0.024$, and 0.032 $\mu \mathrm{m} \mathrm{s}^{-1 \circ} \mathrm{C}^{-1}$ for samples S0, S003, S003w, and S03, respectively). Moreover, the respective $x$-intercepts shown in Fig. 6 were $0.27,0.91,1.47$, and $2.75{ }^{\circ} \mathrm{C}$. The final temperatures for hydrate lens growth, which may correspond to the phase equilibrium temperature, were estimated to be $4.13,3.49,2.39$, and $1.65^{\circ} \mathrm{C}$, respectively.

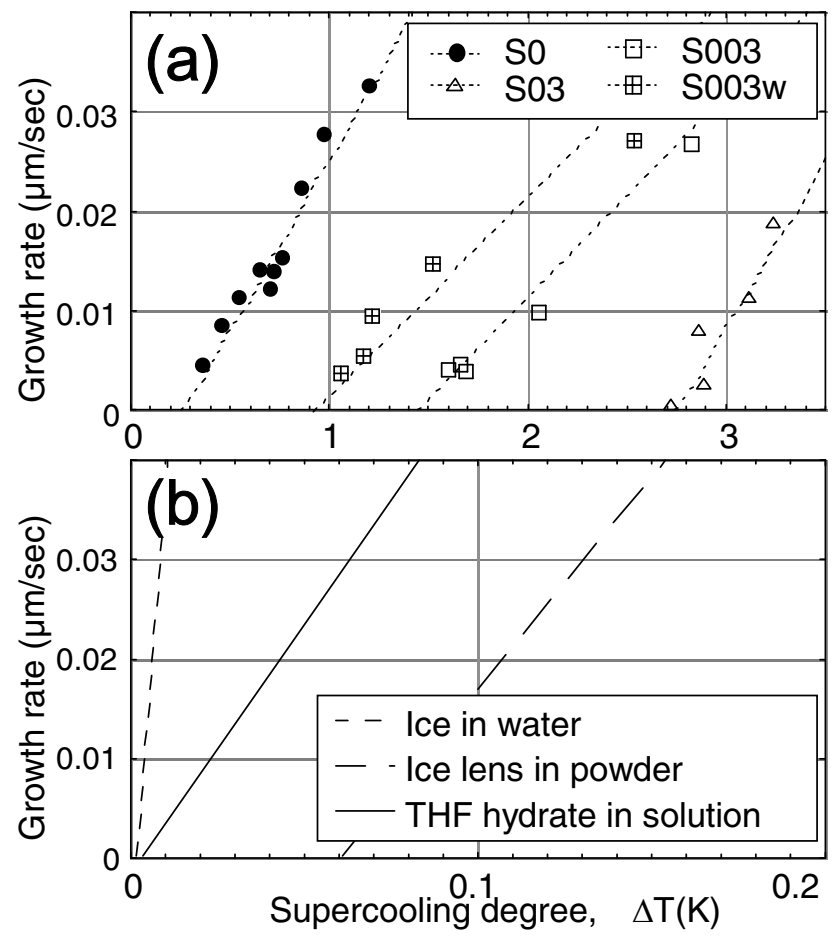

Fig. 6 Growth rate of THF hydrate and the degree of supercooling at the growth surface. (a) THF hydrate in glass powder, (b) ice and THF hydrate in the melt, and an ice lens in glass powder. 
The growth rate of THF hydrate in the THF-water solution per degree of supercooling $\left(0.5 \mu \mathrm{m} \mathrm{s}^{-1}{ }^{\circ} \mathrm{C}^{-1}\right)$ was about $1 / 25$ th the growth rate of ice in water $(12.3$ $\left.\mu \mathrm{m} \mathrm{s}^{-1}{ }^{\circ} \mathrm{C}^{-1}\right)$. This may have arisen from the thermal property differences between THF hydrate and water (Table 2). The growth rate of an ice lens in a powder becomes markedly lower than that of ice in water due to the properties of unfrozen water (structured water) near the ice lens (Watanabe 2002). The ratio of the growth rate of a hydrate lens $\left(0.02 \mu \mathrm{m} \mathrm{s}^{-1}{ }^{\circ} \mathrm{C}^{-1}\right)$ to that of THF hydrate in a solution without porous particles was 1:25, which was the same as the ratio of the growth rate of an ice lens $\left(0.43 \mu \mathrm{m} \mathrm{s}^{-1}{ }^{\circ} \mathrm{C}^{-1}\right)$ to that of ice in water. The water structuring near $\mathrm{THF}$ hydrate may play important roles in the formation of hydrate lenses.

\section{Discussion}

The molar depression of the melting temperature, $\Delta T_{m}$, of a bulk solution with the molar concentration of $C$ is given by $\Delta T_{m}=i K C$, where $i$ is the dissociation constant of the solute and $K$ is the molar melting point constant of the solvent. If we denote the depression of the melting temperature due to the existence of glass particles as $\Delta T_{m p}$, the equilibrium temperature at the growth surface of the warmest hydrate lens, $T_{g s}$, would be approximated as $T_{g s}=4.4-\Delta T_{m}-\Delta T_{m p} . \quad T_{g s}$ can be obtained from the $x$-intercept in Fig. 6, and $\Delta T_{m p}$ can be estimated from the experimental result for S0 as $0.27{ }^{\circ} \mathrm{C}$. Assuming that the dissociation constant of sodium chloride in THF solution is 2 , and the molar depression of THF solution is the same as that of water $\left(1.86{ }^{\circ} \mathrm{C} \mathrm{kg} \mathrm{mol}^{-1}\right)$, we obtain sodium chloride concentrations of the THF solution of $1.9,3.9$, and $7.0 \%$ for samples S003, S03, and S3, respectively. These concentrations are 2.3-63 times greater than their initial concentrations. This shows that the warmest hydrate lens grew while rejecting sodium chloride, which resulted in the formation of a concentration gradient near the growth surface.

Using interferometry, Nagashima et al. (2000) observed a salt concentration field near THF hydrate, which grew at a constant rate of $5 \mu \mathrm{m} \mathrm{s}^{-1}$ in sodium chloride solution with an initial concentration of $3 \%$, and indicated that the concentration increased from 4.5 to $5.6 \%$ near the growth surface. Although the growth rate observed in our experiment was slower than that in their experiment (Fig. 6: slower than $0.05 \mu \mathrm{m} \mathrm{s}^{-1}$ ), a higher concentration of salt near the growth surface was observed. In addition, the temperature at the growth surface of the hydrate lens in sample S003w, which had a lower numerical density of glass particles, was higher than that in sample S003 (Fig. 5). It is thought that the particles inhibit the mobility of sodium or chloride ions near the hydrate lens.

A greater increase in the salt concentration near the growth surface (Csurface /Cinit ) was prominent in the sample with the lower initial salt concentration. A similar tendency has also been reported in the formation of an ice lens in the glass powder media (Watanabe 2001), showing the similarity in the growth processes of hydrate lenses and ice lenses. 


\section{Conclusions}

Directional cooling experiments were conducted to clarify the fundamental mechanism of the formation and frost heave of clathrate hydrate in porous media, such as soil. The sequential formation of lenslike clathrate hydrate was observed in glass powder saturated with a THF-water solution. When sodium chloride was added to the solution, the growth of the clathrate hydrate was dendrite-like depending on the sodium chloride concentration. The growth rate of the THF hydrate lens was proportional to the degree of supercooling at the growth surface. The degree of supercooling decreased with increasing sodium chloride concentration, resulting in a decrease in the growth rate. These results are similar to ice lens formation in glass powder and soil (frost heave). Considering the differences in thermal properties, knowledge of frost heave should facilitate our understanding of the mechanism of clathrate hydrate formation in soil.

\section{References}

Chuvilin, E. M., Perlova, E. V., Makhonina N. A. and Yakushev, V. S. (2000). "Research of hydrate and ice formation in soils during cyclic fluctuations of temperature." Ground Freezing,. 9-14, Balkema, Rotterdam.

Chuvilin, E. M., Makhonina, N. A., Titenskaya, O. A. and Boldina, O. M. (2002). "Petrophysical investigations on frozen sediments artificially saturated by hydrate." Proceedings of the Fourth International Conference on Gas Hydrates, 734-739.

Dallimore, S. R. and Collett, T. S. (1997). "Gas hydrates associated with deep permafrost in the Mackenzie delta, N. W. T., Canada: Regional overview." Proceedings of the Seventh International Conference on Permafrost, 201-206.

de Roo, J. L. and Peter, C. J. (1983). "Occurrence of Methane hydrate in saturated and unsaturated solutions of sodium chloride and water in dependence of temperature and pressure." AIChE Journal, 29, 651-657.

Devarakonda, S., Groysman, A. and Myerson, A. S. (1999). "THF-water hydrate crystallization: an experimental investigation." Journal of Crystal Growth, 204, 525-538.

Gillen, K. T., Douglass, D. C. and Houch, M. J. R. (1972). "Self-diffusion in liquid water to $-31^{\circ} \mathrm{C}$." The Journal of Chemical Physics, 57, 5117-5119.

Gough, S. R. and Davidson, D. W. (1971). "Composition of tetrahydrofuran hydrate and the effect of pressure on the decomposition." Canadian Journal of Chemistry, 49, 2691-2699.

Handa, Y. P., Hawkins, R. E. and Murray, J. J. (1984). "Calibration and testing of a Tian-Calvet heat-flow calorimeter: Enthalpies of fusion and heat capacities for ice and tetrahydrofuran hydrate in the range 85 to 270K." Journal of Chemical Thermodynamics, 16, 623-632. 
Hanley, H. J. M., Meyers, G. J., White, J. W. and Sloan, E. D. (1989). "The melting curve of THF hydrate in $\mathrm{D}_{2} \mathrm{O}$." International Journal of Thermophysics, 10 , 903-909.

Hiroi, M., Mizusaki, T., Tsuneto, T., Hirai, A., and Eguchi, K. (1989). "Frost heave phenomena of helium on porous glasses." Physical Review B, 40, 6581-6590.

Iida, T., Mori, H., Mochizuki, T. and Mori, Y. H. (2001). "Formation and dissociation of clathrate hydrate in stoichiometric tetrahydrohuran-water mixture subjected to one-directional cooling or heating." Chemical Engineering Science, 56, 4747-4758.

Leaist, D. G., Murray, J. J., Post, M. L. and Davidson, D. W. (1982). "Enthalpies of decomposition and heat capacities of ethylene oxide and tetrahydrofuran hydrates." Journal of Physical Chemistry, 86, 4175-4178.

Mak, T. C. W. and McMullan, R. K. (1965). "Polyhedral Clathrate hydrates. X. Structure of the double hydrate of tetrahydrofuran and hydrogen sulfide." The Journal of Chemical Physics, 42, 2732-2737.

Mutou, Y., Watanabe, K., Ishizaki, T., and Mizoguchi, M. (1998). "Microscopic observation of ice lensing and frost heave in glass beads." Proceedings of 7th International Conference on Permafrost, 783-787.

Nagashima, K., Yamamoto, Y. Takahashi, M. and Komai, T. (2000). "Non-equilibrium salt concentration distribution near growing and melting interface of tetrahydrofuran clathrate hydrate." Science and Technology of High Pressure, 1, 573-576.

Rueff, R. M. and Sloan E. D. (1985). "Effect of granular sediment on some thermal properties of tetrahydrofuran hydrate." Industrial and Engineering Chemistry Process Design Development, 24, 883-885.

Ross, R. G., Andersson, P. and Bäckström, G. (1981). "Unusual PT dependence of thermal conductivity for a clathrate hydrate." Nature, 290, 322-323.

Ross, R. G. and Andersson, P. (1982). "Clathrate and other solid phases in the tetrahydrofuran gas hydrate." Canadian Journal of Physics and Chemistry, 60, 881-892.

Sloan, E. D. (1990). Clathrate hydrates of natural gases. Marcel Dekker Inc, New York.

Zhu, D. M., Vilches, O. E., Dash, J. G. and Wettlaufer, J. S. (2000). "Frost heave in argon." Physical Review Letters, 85, 4908-4911.

Uchida, T., Ebinuma, T., Kawabata, J. and Narita, H. (1999). "Microscopic observation of formation processes of clathrate-hydrate films at an interface between water and carbon dioxide." Journal of Crystal Growth, 204, 348-356.

Watanabe, K., Muro, Y. and Mizoguchi, M. (2001). "Water and solute distributions near an ice lens in a glass-powder medium saturated with sodium chloride solution under unidirectional freezing." Crystal Growth \& Design, 1, 207-211.

Watanabe, K. (2002). "Relationship between growth rate and supercooling in the formation of ice lenses in a glass powder." Journal of Crystal Growth, 237-239, 2194-2198. 